\title{
Terpenoids, Flavonoids and other Constituents of Eupatorium betonicaeforme (Asteraceae)
}

\author{
Maria Rose Jane R. Albuquerque, Andreza Maria L. Pires, Otília Deusdênia L. Pessoa* \\ and Edilberto R. Silveira
}

\author{
Curso de Pós-Graduação em Química Orgânica, Departamento de Química Orgânica e Inorgânica, Universidade \\ Federal do Ceará, CP 12200, 60021-970 Fortaleza - CE, Brazil
}

\begin{abstract}
Um novo diterpeno kaureno, caracterizado como ácido 15 $\alpha$-decanoiloxi-kaur-16-en-19-óico, juntamente com os compostos conhecidos: ácido pentacosanóico, $24 \alpha$-etil-5 $\alpha$-colesta-7,22E-dien$3 \beta$-ol, ácido $15 \alpha$-hidroxi-kaur-16-en-19-óico, $8 \beta$-angeloil- $9 \beta, 10 \beta$-diidroxi-1-oxo-germacra$4 E, 11$ (13)dien-12,6 $\alpha$-olideo, $3 \beta$-hidroxiicosan-1,5 $\beta$-olideo, acetate de taraxasterila, 7-Ometilcampferol, caempferol e nepetina foram isolados das flores de Eupatorium betonicaeforme. Adicionalmente, foram isolados das partes aéreas, o acetato de taraxasterila e a mistura binária de $\alpha$ - e $\beta$-amirina, enquanto foram obtidos das raízes, a mistura de $\beta$-sitosterol e estigmasterol, e 6acetil-2,2-dimetilcroman-4-ona. A elucidação estrutural de todos os compostos isolados neste trabalho foi realizada por análise espectroscópica e comparação com dados descritos na literatura.
\end{abstract}

A new acylated kaurene diterpene, characterized as 15 $\alpha$-decanoyloxy-kaur-16-en-19-oic acid, along with nine known compounds: pentacosanoic acid, $24 \alpha$-ethyl-5 $\alpha$-cholesta-7,22Edien-3 $\beta$-ol, $15 \alpha$-hydroxy-kaur-16-en-19-oic acid, $8 \beta$-angeloyloxy-9 $\beta, 10 \beta$-dihydroxy-1-oxogermacra-4E,11(13)dien-12,6 $\alpha$-olide, $3 \beta$-hydroxyeicosan-1,5 $\beta$-olide, taraxasteryl acetate, 7-Omethylkaempferol, kaempferol, and nepetin were isolated from the flowers of Eupatorium betonicaeforme (Asteraceae). In addition, from the aerial parts were isolated taraxasteryl acetate and $\alpha$-and $\beta$-amyrin, while the mixture of $\beta$-sitosterol and stigmasterol, and 6-acetyl-2,2dimethylchroman-4-one were isolated from the roots. The structure elucidation of all compounds was performed by spectroscopic analysis and comparison with published data from literature.

Keywords: Eupatorium betonicaeforme, Asteraceae, triterpenes, diterpenes, flavonoids, lactones

\section{Introduction}

The genus Eupatorium (family Asteraceae, tribe Eupatorieae, subtribe Eupatoriinae), is a taxonomically complex group of species with distribution centers mainly in Europe, eastern Asia and North America. ${ }^{1}$ Several studies on Eupatorium species have been reported, revealing a great number and diversity of secondary metabolites, where the sesquiterpenes lactones of the guaianolide, ${ }^{2}$ germacranolide, ${ }^{3}$ heliangolide, ${ }^{4}$ and eudesmanolide types ${ }^{5}$ are the most characteristic compounds. Flavonoids, ${ }^{6}$ diterpenes, ${ }^{7}$ benzofurans, ${ }^{8}$ pyrrolizidine alkaloids, ${ }^{9}$ chromenes ${ }^{10}$ and thymol derivatives ${ }^{11}$ are also common. Triterpenes, ${ }^{12}$ sesquiterpenes, ${ }^{13}$ coumarins ${ }^{14}$ and $\delta$-lactones of the long chain type ${ }^{15}$ have been occasionally isolated. A great number of Eupatorium species are employed in traditional medicine in the treatment of different pathologies. Indeed, a significant number of bioactive natural compounds have been reported from this renowned genus. ${ }^{16-19}$

As part of a continuing search on native plants from Northeast of Brazil, particularly of the Asteraceae family, the volatile oils from the roots and leaves of $E$. betonicaeforme yielded 2,2-dimethyl-6-vinylchroman-4one (1) and 2-senecioyl-4-vinylphenol (2), the sesquiterpenes $\beta$-caryophyllene, $\gamma$-muurolene and bicyclogermacrene as the main constituents. Both oils showed larvicidal effects against Aedes aegypti larvae, particularly the oil from the roots. ${ }^{20}$ The major constituents ( $\mathbf{1}$ and $\mathbf{2}$ ) were isolated and tested. Compound $\mathbf{1}$ was the most active compound and is probably responsible for the larvicidal effect. ${ }^{20}$ Continuing with the phytochemical investigation of $E$. betonicaeforme this paper reports now its nonvolatile chemical composition.

*e-mail: opessoa@ufc.br 


\section{Results and Discussion}

The extract of the flowers of $E$. betonicaeforme, after successive column chromatography on Si gel, afforded the new secondary metabolite $15 \alpha$-decanoyloxy-kaur-16-en-19oic acid (3), together with the known compounds: pentacosanoic acid (4), $24 \alpha$-ethyl-5 $\alpha$-cholesta-7,22E-dien$3 \beta$-ol (5), ${ }^{21} 15 \alpha$-hydroxy-kaur-16-en-19-oic acid (6), ${ }^{22} 8 \beta$ angeloyloxy-9 $\beta, 10 \beta$-dihydroxy-1-oxo-germacra$4 E, 11$ (13)dien-12,6 $\alpha$-olide (7), ${ }^{23} 3 \beta$-hydroxyeicosan-1,5 $\beta$ olide (8), ${ }^{24}$ taraxasteryl acetate $(\mathbf{9}),{ }^{25}$ 7-O-methylkaempferol (10), kaempferol (11), and nepetin (12). ${ }^{26}$ From the hexane extract of the aerial parts (leaves and stems) were isolated taraxasteryl acetate (9) and $\alpha$ - and $\beta$-amyrin (13 and 14), ${ }^{25}$ while from the hexane extract of roots were obtained a mixture of $\beta$-sitosterol and stigmasterol (15 and 16) and 6-acetyl-2,2-dimethylchroman-4-one (17), ${ }^{27}$ Figure 1. All of the known compounds were identified by comparison of their spectral data with those reported in the literature. Compound 7 was previously isolated from Trichogonia salviaefolia (Asteraceae) by Bohlmann et al., and its molecular structure has been deduced by ${ }^{1} \mathrm{H}$ NMR and MS..${ }^{23}$ Complete ${ }^{1} \mathrm{H}$ and
${ }^{13} \mathrm{C}$ NMR chemical shifts of 7 , which were assigned by a combination of 1D and 2D NMR techniques, are listed in Table 1.

Compound $\mathbf{3}$ was isolated as a colorless waxy solid. The molecular formula $\mathrm{C}_{30} \mathrm{H}_{48} \mathrm{O}_{4}$ was deduced by a combination of EIMS ([M] $\left.]^{+}, m / z 472\right)$ and ${ }^{13} \mathrm{C}$ NMR data. The ${ }^{13} \mathrm{C}$ NMR spectrum showed a total of 30 carbon signals, among the characteristic signals at $\delta_{\mathrm{C}} 29.9-29.3$ and 14.3 consistent with the presence of aliphatic methylene groups of a fatty acyl moiety. The deshielded carbon signals at $\delta_{\mathrm{C}} 184.8$ and 174.1 indicated the presence of two carbonyl groups compatible with the presence of carboxylic acid and ester functions, respectively. IR absorption bands at 1730 and $1694 \mathrm{~cm}^{-1}$ further supported these findings. The additional deshielded carbon signals at $\delta_{\mathrm{C}}$ at 155.7 and 110.0 , as well the proton signal at $\delta_{\mathrm{H}} 5.26(2 \mathrm{H}$, brs) clearly demonstrated the presence of an exomethylene moiety. In the HMBC spectrum were observed correlations for the exocyclic double-bond protons $\left(\delta_{\mathrm{H}} 5.26\right)$ with the oxymethine carbon signal at $\delta_{\mathrm{C}} 82.9$ revealing the contiguity of these units. Comparison of the chemical shifts with the literature data indicated the presence of a kaur-16-en-19-oic acid bearing an oxygen atom at C-

Table 1. ${ }^{1} \mathrm{H}$ and ${ }^{13} \mathrm{C}$ NMR data for compounds $3\left(\mathrm{CDCl}_{3}\right)$ and $\mathbf{7}$ (acetone- $\left.\mathrm{d}_{6}\right)$

\begin{tabular}{|c|c|c|c|c|}
\hline \multirow[b]{2}{*}{$\mathrm{C}$} & \multicolumn{2}{|c|}{3} & \multicolumn{2}{|c|}{7} \\
\hline & $\delta_{\mathrm{C}}$ & $\delta_{\mathrm{H}}(\mathrm{m}, J$ in $\mathrm{Hz})$ & $\delta_{\mathrm{C}}$ & $\delta_{\mathrm{H}}(\mathrm{m}, J$ in $\mathrm{Hz})$ \\
\hline 1 & 37.8 & $2.15(\mathrm{~d}, J 13.1)$ & 216.6 & - \\
\hline \multirow[t]{2}{*}{2} & 19.2 & $1.44(\mathrm{~m})$ & 39.1 & $3.64(\mathrm{td}, J 13.6 ; 3.0)$ \\
\hline & & $1.60(\mathrm{~m})$ & & $2.25(\mathrm{dt}, J 13.6 ; 3.7)$ \\
\hline 3 & 34.9 & $1.44(\mathrm{~m})$ & 36.8 & $2.95(\mathrm{~m}) 2.15(\mathrm{dt}, J 11.9 ; 3.0)$ \\
\hline 4 & 43.9 & - & 145.4 & - \\
\hline 5 & 56.8 & $1.09(\mathrm{~d}, J$ 11.9) & 126.4 & $4.90(\mathrm{br} \mathrm{d}, J 10.4)$ \\
\hline \multirow[t]{2}{*}{6} & 20.9 & $1.86(\mathrm{~m})$ & 76.3 & $5.21(\mathrm{dd}, J 7.8 ; 10.4)$ \\
\hline & & $1.77(\mathrm{~m})$ & & \\
\hline 7 & 40.7 & $1.86(\mathrm{~m})$ & 50.4 & $2.83^{\mathrm{c}}$ \\
\hline 8 & 47.6 & - & 71.7 & $5.86(\mathrm{dd}, J 2.5 ; 4.0)$ \\
\hline 9 & 53.1 & $1.29-1.25$ & 80.1 & $4.35(\mathrm{dd}, J 4.0 ; 6.4)$ \\
\hline 10 & 40.0 & - & 82.0 & - \\
\hline 11 & 18.6 & $1.60(\mathrm{~m})$ & 138.2 & - \\
\hline 12 & 32.8 & $1.60(\mathrm{~m}) ; 1.49$ & 169.8 & - \\
\hline 13 & 42.7 & $2.77(\mathrm{br} \mathrm{s})$ & 120.4 & $6.11(\mathrm{~d}, J 3.2) 5.43(\mathrm{~d}, J 3.2)$ \\
\hline 14 & 37.4 & $1.96(\mathrm{~d}, J 11.5) ; 1.44$ & 26.1 & $1.48(\mathrm{~s})$ \\
\hline 15 & 82.9 & $5.26(\mathrm{~s})$ & 19.4 & $1.87(\mathrm{~d}, J 1.3)$ \\
\hline 16 & 155.7 & - & - & - \\
\hline 17 & 110.0 & $5.07(\mathrm{~s})$ & - & - \\
\hline 18 & 29.0 & $1.23(\mathrm{~s})$ & - & - \\
\hline 19 & 184.8 & - & - & - \\
\hline 20 & 15.9 & $0.95(\mathrm{~s})$ & - & - \\
\hline 1 , & 174.1 & - & 167.1 & - \\
\hline $2^{\prime}$ & 34.9 & $2.91(\mathrm{t}, J 7.5)$ & 128.7 & - \\
\hline $3^{\prime}$ & 25.3 & $1.60(\mathrm{~m})$ & 139.2 & $6.13(\mathrm{~m})$ \\
\hline $4^{\prime}$ & & & 16.1 & $1.93(\mathrm{dq}, J 1.4 ; 7.3)$ \\
\hline 5, & & & 20.8 & 1.82 (quint. $J 1.4$ ) \\
\hline 6 & $29.9-29.3^{\mathrm{a}}$ & $1.29-1.25(\mathrm{~m})^{\mathrm{b}}$ & - & - \\
\hline 7 ' & & & - & - \\
\hline $8^{\prime}$ & 32.0 & & - & - \\
\hline 9' & 22.8 & & - & - \\
\hline 10 ' & 14.3 & $0.87(\mathrm{t}, J 6.4)$ & - & - \\
\hline
\end{tabular}

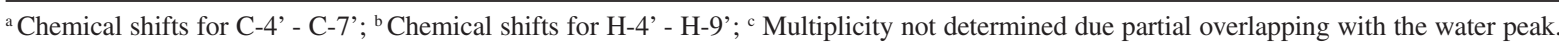


<smiles>[R]c1ccc2c(c1)C(=O)CC(C)(C)O2</smiles>

$1 \mathrm{R}=\mathrm{CH}=\mathrm{CH}_{2}$ $15 \mathrm{R}=\mathrm{COCH}_{3}$<smiles></smiles><smiles>CCC(/C=C/C(C)C1CCC2C3=CC=C4CC(O)CCC4(C)C3CCC21C)C(C)C</smiles>

$5 \triangle^{7,22}$

$15 \triangle^{5}$

$16 \triangle^{5,22}$

$\mathrm{CH}_{3}\left(\mathrm{CH}_{2}\right)_{22} \mathrm{CH}_{2} \mathrm{CO}_{2} \mathrm{H}$

4

Figure 1. Chemical constituents isolated from E. betonicaeforme.

15..$^{22,28}$ This fact was also reinforced by the EIMS, which showed an intense ion peak at $m / z 318\left(\mathrm{C}_{20} \mathrm{H}_{30} \mathrm{O}_{3}\right)$ related to a proton rearrangment followed by loss of the fatty side chain. In accordance with published data, it was assumed that diterpene 3 belongs to the ent-series, like the other kaurenes previously isolated from Eupatorium. ${ }^{28,29}$ Additional support for this affirmation was the small negative specific rotation $\left([\alpha]_{\mathrm{D}}^{20}-0.66^{\circ}, c 0.05, \mathrm{CHCl}_{3}\right)$, which is characteristic of entkaurenes. ${ }^{30}$ The location of the acyl moiety was supported by the long-range correlation of the oxymethine proton at $\delta_{\mathrm{H}}$ $5.26(\mathrm{H}-15)$ with the ester carbonyl signal at $\delta_{\mathrm{C}} 174.1$, while the $\alpha$-orientation of this unit was inferred by comparison of the ${ }^{13} \mathrm{C}$ NMR data with those from cinannamoylgrandifloric

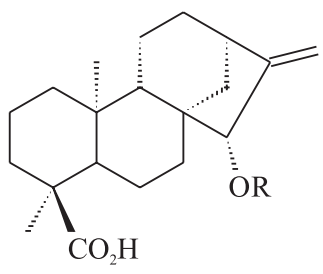

$3 \mathrm{R}=\mathrm{COCH}_{2}\left(\mathrm{CH}_{2}\right)_{7} \mathrm{CH}_{3}$ $6 \mathrm{R}=\mathrm{H}$<smiles>[R]c1cc(-c2oc3cc([R2])c([R])c(O)c3c(=O)c2[R])ccc1O</smiles>

$10 \mathrm{R}^{1}=\mathrm{CH}_{3}, \mathrm{R}^{2}=\mathrm{R}^{4}=\mathrm{H}, \mathrm{R}^{3}=\mathrm{OH}$

$11 \mathrm{R}^{1}=\mathrm{R}^{2}=\mathrm{R}^{4}=\mathrm{H}, \mathrm{R}^{3}=\mathrm{OH}$

$12 \mathrm{R}^{1}=\mathrm{R}^{3}=\mathrm{H}, \mathrm{R}^{2}=\mathrm{OCH}_{3}, \mathrm{R}^{4}=\mathrm{OH}$<smiles>C=C1CC[C@]2(C)CC[C@H]3C(CCC4[C@@]3(C)CCC3C(C)(C)C(OC(C)=O)CC[C@@]34C)C2[C@@H]1C</smiles>

9<smiles>[R]C=[R]([H])C=[R]([R])[R]</smiles>

acid. ${ }^{22}$ Thus, the structure of $\mathbf{3}$, a new ent-kaurene derivative, was established as $15 \alpha$-decanoyloxy-16-kauren-19-oic acid. Although the labdanes are the most frequently encountered diterpenes in plants of the genus Eupatorium, ent-kauranes are not uncommon. ${ }^{28,29}$

\section{Experimental}

\section{General experimental procedures}

Melting points were determined using a digital Mettler Toledo FP90 apparatus. The optical rotations were measured on a Perkin-Elmer 341 digital polarimeter. IR spectra were 


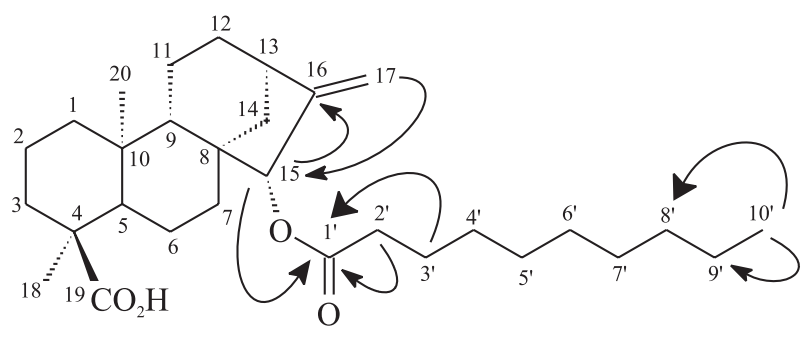

3

Figure 2. Selected HMBC correlations for compound 3.

recorded using a Perkin-Elmer FT-IR 1000 spectrometer. EIMS was acquired with the direct insertion probe on a GCMS Shimadzu spectrometer at $70 \mathrm{eV}$. NMR spectra were recorded on a Bruker Avance DRX-500 $\left(500 \mathrm{MHz}\right.$ for ${ }^{1} \mathrm{H}$ and $125 \mathrm{MHz}$ for $\left.{ }^{13} \mathrm{C}\right)$ or DPX-300 (300 MHz for ${ }^{1} \mathrm{H}$ and 75 $\mathrm{MHz}$ for ${ }^{13} \mathrm{C}$ ) spectrometers. Chemical shifts, given on the $\delta$ scale, were referenced to the residual undeuterated portion of the deuterated organic solvent, for proton $\left[\left(\mathrm{CD}_{3}\right)_{2} \mathrm{CO}: \delta_{\mathrm{H}}\right.$ $2.05 ; \mathrm{CDCl}_{3}: \delta_{\mathrm{H}}$ 7.27], and the center peak of the deuterated solvent [ $\left.\left(\mathrm{CD}_{3}\right)_{2} \mathrm{CO}: \delta_{\mathrm{C}} 206.68,29.92 ; \mathrm{CDCl}_{3}: \delta_{\mathrm{C}} 77.23\right]$. Column chromatography was run using silica gel 60 (70 230 mesh, VETEC) and silica gel $60(0.063-0.200 \mathrm{~mm}$, MERCK). TLC was performed on precoated silica gel polyester sheets (Kieselgel $60 \mathrm{~F}_{254}, 0.20 \mathrm{~mm}$, Merck) by detection with a spray reagent of vanillin/perchloric acid/ EtOH solution followed by heating at $120{ }^{\circ} \mathrm{C}$.

\section{Plant material}

Eupatorium betonicaeforme in the flowering stage was collected in May 2002, from Acarape County, Ceará, and identified by Prof. Elnatan B. Souza of the Universidade Estadual Vale do Acaraú - Ceará. Voucher specimen (\# 29.104) has been deposited at the Herbario Prisco Bezerra (EAC) of the Departamento de Biologia, Universidade Federal do Ceará.

\section{Extraction and isolation}

Air-dried and powdered E. betonicaeforme parts were extracted with hexane: flowers $(0.8 \mathrm{~kg}, 2 \times 4 \mathrm{~L})$, aerial parts $(2.5 \mathrm{~kg}, 2 \times 9 \mathrm{~L})$ and roots $(0.7 \mathrm{~kg}, 2 \times 3$ L), followed by EtOH with same amounts of solvent. After evaporation of the solvents under reduced pressure afforded the crude hexane and EtOH extracts, respectively: flowers $(15.9 \mathrm{~g}$ and $82.9 \mathrm{~g})$, aerial parts $(51.6 \mathrm{~g}$ and $75.9 \mathrm{~g})$, and roots $(4.6 \mathrm{~g}$ and $18.0 \mathrm{~g})$. The hexane extract from the flowers $(15.9 \mathrm{~g})$ was fractioned over Si gel to yield the follow fractions: hexane $(0.4$ g), hexane/EtOAc 8:2 (14.0 g), hexane/EtOAc 1:1 (0.8 g) and EtOAc $(0.3 \mathrm{~g})$. The hexane/EtOAc fraction 8:2
(14.0 g) was chomatographed over Si gel, eluting with hexane/EtOAc (9:1, 1:1), EtOAc, and $\mathrm{MeOH}$ to afford four fractions (F1-F4). F4 (8.7 g, hexane/EtOAc 9:1) was subjected to successive Si gel flash column chromatography using hexane/EtOAc 9.5:0.5 to yield $3(80.0 \mathrm{mg})$ and pentacosanoic acid $4(12.0 \mathrm{mg})$. Similarly, F2 (1.7 g, hexane/EtOAc 1:1) was subjected to repeated $\mathrm{Si}$ gel flash column chromatography using hexane/EtOAc 9:1 mixture to yield $5(13.0 \mathrm{mg})$ and $\mathbf{6}$ $(5.8 \mathrm{mg})$. The hexane/EtOAc fraction 1:1 (0.8 g) was subjected to Si gel flash column chromatography using $\mathrm{CHCl}_{3} /$ EtOAc 9:1 to give 145 subfractions of $10 \mathrm{~mL}$ each. $7(16.0 \mathrm{mg})$ was isolated from fractions $65-72$, while $8(21.0 \mathrm{mg})$ was obtained from fractions 89-105. The EtOH extract of the flowers $(82.0 \mathrm{~g})$ was suspended in $\mathrm{MeOH} / \mathrm{H}_{2} \mathrm{O} 3: 1$ and partitioned with $\mathrm{CH}_{2} \mathrm{Cl}_{2}$, EtOAc, and $n$ - $\mathrm{BuOH}$. The $\mathrm{CH}_{2} \mathrm{Cl}_{2}$ extract was evaporated under reduced pressure yielding a residue $(24.0 \mathrm{~g})$, which was fractioned over $\mathrm{Si}$ gel and eluted with hexane/EtOAc $(7.5: 2.5,1: 1,2.5: 7.5)$ and EtOAc. The hexane/EtOAc (7.5:2.5) fraction (4.0 g) was chromatographed over $\mathrm{Si}$ gel eluting with hexane/EtOAc $(9: 1,8: 2,7: 3,1: 1)$, EtOAc and $\mathrm{MeOH}$ to afford seven fractions (F1-F7). F2 (1.2 g) was subjected to Si gel flash column chromatography using hexane/EtOAc (9.9:0.1) to afford $9(40.0 \mathrm{mg})$, while from fraction F6 $(0.1 \mathrm{~g})$, using the same chromatographic procedure and the solvent system hexane/EtOAc (7:3) was isolated $\mathbf{1 0}(3.0 \mathrm{mg})$. The hexane/EtOAc (1:1) fraction (1.1 g) was subjected to Si gel flash column chromatography eluting with a $\mathrm{CHCl}_{3} /$ EtOAc (8:2) gradient to yield $\mathbf{1 1}(4.2 \mathrm{mg})$ and $12(370.0 \mathrm{mg})$. The hexane extract from the aerial parts $(51.0 \mathrm{~g})$ was fractioned over Si gel eluting with hexane, $\mathrm{CHCl}_{3}$ and EtOAc. The hexane fraction $(25.0 \mathrm{~g})$ was chromatographed over $\mathrm{Si}$ gel using petroleum ether, $\mathrm{CH}_{2} \mathrm{Cl}_{2}$ and EtOAc as eluent. An aliquot of the petroleum ether fraction $(1.5 \mathrm{~g})$ was subjected to hydrolysis with $\mathrm{KOH}$ solution to yield a free fatty acids mixture $(0.07 \mathrm{~g})$ and an unsaponifiable fraction $(0.7$ g). Methylation of the fatty acids with $\mathrm{MeOH} / \mathrm{HCl}$ (1.0\%) followed by GC/MS analysis of the methyl esters mixture allowed the identification of: hexadecanoic $(65.0 \%)$, heptadecanoic $(1.2 \%)$, octadecanoic $(7.3 \%)$, eicosanoic $(3.5 \%)$, docosanoic $(9.0 \%)$, tricosanoic $(1.0 \%)$, and tetracosanoic acids (3.5\%). TLC analysis indicated that the $\mathrm{CH}_{2} \mathrm{Cl}_{2}$ fraction $(9.8 \mathrm{~g})$ was rich in compound $\mathbf{9}$, which was recrystallized in acetone to afford taraxasteryl acetate $(736.0 \mathrm{mg})$. The $\mathrm{CH}_{2} \mathrm{Cl}_{2}$ fraction $(21.0 \mathrm{~g})$ after successive $\mathrm{Si}$ gel column chromatography using hexane and increasing amounts of EtOAc afforded a binary mixture of $\mathbf{1 3}$ and $\mathbf{1 4}$ (7.0 
$\mathrm{mg})$. The hexane fraction from the roots $(4.6 \mathrm{~g})$ was fractioned over $\mathrm{Si}$ gel eluting with hexane, hexane/ $\mathrm{CH}_{2} \mathrm{Cl}_{2} 1: 1, \mathrm{CH}_{2} \mathrm{Cl}_{2}$ and EtOAc. From the fraction hexane $/ \mathrm{CH}_{2} \mathrm{Cl}_{2}(1: 1)$ fraction (1.6 g) was obtained a mixture of $\mathbf{1 5}$ and $\mathbf{1 6}$ (30.0 mg). The EtOH extract was fractioned over Si gel eluting with hexane/EtOAc (8:2, 6:4, 4:6, 2:8), EtOAc and MeOH. The hexane/EtOAc $(8: 2)$ fraction $(2.7 \mathrm{~g})$ was subjected to successive $\mathrm{Si}$ gel column chromatography using increasing amounts of EtOAc in hexane to yield $17(42.0 \mathrm{mg})$.

15 $\alpha$-Decanoyloxy-kaur-16-en-19-oic acid (3). Colorless waxy solid; $[\alpha]_{\mathrm{D}}^{20}-0.66^{\circ}\left(c 0.05, \mathrm{CHCl}_{3}\right)$; IR $(\mathrm{KBr}) v_{\max }$ ' $\mathrm{cm}^{-1}$ : 3350-2700, 1730, 1694, 1464, 1242, 1165; EIMS $(70 \mathrm{eV}) \mathrm{m} / \mathrm{z} 472[\mathrm{M}]^{+}(5), 318$ (25), 300 (80), 285 (90), 255 (50), 104 (65), 91 (45), 71 (82), 57 (100); ${ }^{1} \mathrm{H}$ (500 $\mathrm{MHz})$ and ${ }^{13} \mathrm{C}$ NMR (125 MHz) data, Table 1.

$8 \beta$-Angeloyl-9 $\beta, 10 \beta$-dihydroxy-1-oxo-germacra4E,11(13)dien-12,6 $\alpha$-olide (7). Colorless needles; mp 164$165^{\circ} \mathrm{C} ;[\alpha]_{\mathrm{D}}^{20}-0.24^{\circ}$ (c 0.05 , acetone); IR (KBr) $v_{\max } / \mathrm{cm}^{-1}$ : 3437, 2929, 1736, 1699, 1154, 1107; EIMS m/z 378 [M] ${ }^{+}$ (absent), 312 (10), 295 (5), 277 (15), 260 (12), 232 (20), 207 (12), 108 (13), 83 (100); ${ }^{1} \mathrm{H}(500 \mathrm{MHz})$ and ${ }^{13} \mathrm{C}$ NMR (125 MHz) data, Table 1.

\section{Acknowledgments}

The authors acknowledge the financial support provided by the Brazilian Agencies CNPq, CAPES, FUNCAP and PRONEX.

\section{References}

1. King, R M.; Robinson, H.; The Genera of the Eupatorieae (Asteraceae). Monographs in Systematic Botany, Missouri Botanical Garden: United States, 1987, vol. 22, p. 65.

2. Bohlmann, F.; Mahantan, P. K.; Suwita, A.; Natu, A. A.; Zdero, C.; Dorner, W.; Ehlers, D.; Grenz, M.; Phytochemistry 1977, 16, 1973.

3. Bohlmann, F.; Banerjee, S.; King, R. M.; Robinson, H.; Phytochemistry 1984, 23, 1189.

4. Boeker, R.; Jakupovic, J.; Bohlmann, F.; King, R. M.; Robinson, H.; Phytochemistry 1986, 25, 1669.

5. González, A.G.; Barrera, J. B.; Hernández, A. C. Y.; Rosas, F. E.; Dominguez, X. A.; Phytochemistry 1985, 24, 1847.

6. Oliveira, B. H.; Nakashima, T.; Souza Filho, J. D.; Frehse, F.; J. Braz. Chem. Soc. 2001, 12, 243.

7. Carreras, C. R.; Rossomando, C.; Giordano, O. S.; Phytochemistry 1998, 48, 1031.
8. Rios, M. Y.; Aguilar-Guadarrama, A. B.; Navarro, V.; Planta Med. 2003, 69, 967.

9. Lang, G.; Passreiter, C. M.; Medinilla, B.; Castillo, J. J.; Witte, L.; Biochem. Syst. Ecol. 2001, 29, 143.

10. Bandara, B. M. R.; Hewage, C. M.; Karunaratne, V.; Wannigama, G. P.; Adikaram, N. K. B.; Phytochemistry 1992, 31, 1983.

11. Tori, M.; Ohara, Y.; Nakashima, K.; Sono, M.; J. Nat. Prod. 2001, 64, 1048.

12. Domínguez, X. A.; Quintanilla, G. J. A.; Rojas, M. P.; Phytochemistry 1974, 13, 673.

13. Rücker, G.; Schenkel, E. P.; Manns, D.; Mayer, R.; Heiden, K.; Heinzmann, B. M.; Planta Med. 1996, 62, 565.

14. Herz, W.; Govindan, S.V.; Kumar, N.; Phytochemistry 1981, 20,1343 .

15. Herz, W.; Ramakrishnan, G.; Phytochemistry 1978, 17, 1327.

16. Yang, S. P.; Huo, J.; Wang, Y.; Lou, L. G.; Yue, J. M.; J. Nat. Prod. 2004, 67, 638.

17. El-Seedi, H. R.; Ohara, T.; Sata, N.; Nishiyama, S.; J. Ethnopharmacol. 2002, 81, 293.

18. François, G.; Passreiter, C. M.; Phytother. Res. 2004, 18, 184.

19. Muschietti, L.; Gorzalezany, S.; Ferraro, G.; Acevedo, C.; Martino, V.; Planta Med. 2001, 67, 743.

20. Albuquerque, M. R. J. R.; Silveira, E. R.; Uchôa, D. E. A.; Lemos, T. L. G.; Souza, E. B.; Santiago, G. M. P.; Pessoa, O. D. L.; J. Agric. Food Chem. 2004, 52, 6708.

21. Itoh, T.; Kikuchi, Y.; Tamura, T.; Matsumoto, T.; Phytochemistry 1981, 20, 761.

22. Nascimento, A. M.; Oliveira, D. C. R.; J. Braz. Chem. Soc. 2001, 12, 552.

23. Bohlmann, F.; Zdero, C.; Jakupovic, J.; Gerke, T.; Wallmeyer, M.; King, R. M.; Robinson, H.; Liebigs Ann. Chem. 1984, 162.

24. Gao, F.; Wang, H.; Mabry, T. J.; Watson, W. H.; Kashyap, R. P.; Phytochemistry 1990, 29, 551.

25. Ahmad, V. U.; Rahman, A. U.; Pentacyclic Triterpenoids, Handbook of Natural Products Data, Elsevier: Amsterdam, vol. 2, 1994.

26. Agrawal, P. K.; Thakur, R. S.; Bansal, M. C.; In Studies in Organic Chemistry 39 - Carbon-13 NMR of Flavonoids; Agrawal, P. K., ed.; Elsevier Science Publishing Company Inc.: New York, USA, 1989.

27. Bohlmann, F.; Zdero, C.; Lonitz, M.; Phytochemistry 1977, 16,575 .

28. Herz, W.; Sharma, R. P.; J. Org. Chem. 1976, 41, 1021.

29. Herz, W.; Govindan, S. V.; Blount, J. F.; J. Org. Chem. 1979, 44, 2999.

30. Velandia, J. R.; Carvalho, M. G.; Braz-Filho, R.; Quim. Nova 1998, 21, 397.

Received: June 6, 2005

Published on the web: November 18. 2005 